\title{
Diagnostic indicators in the early recognition of severe cocaine intoxication
}

\author{
T B Hassan, J A Pickett, S Durham, P Barker
}

\begin{abstract}
Acute cocaine intoxication is an ever increasing problem in the United Kingdom. Aggressive resuscitation linked to early diagnosis is essential in preventing death. Three cases of severe cocaine toxicity are presented to highlight certain diagnostic indicators in recognising the condition in patients presenting in a collapsed state to the accident and emergency department. Acidosis was a striking feature. The acute management of such patients is supportive and should involve methods to minimise continuing absorption.
\end{abstract}

(f Accid Emerg Med 1996;13:261-263)

Key terms: cocaine; diagnostic indicators

Severe cocaine toxicity is a life threatening emergency. Most fatal cases deteriorate rapidly and many die before reaching hospital. In those who present to the accident and emergency (A\&E) department early recognition can be difficult. This is usually because of a lack of history from a patient in extremis. However, severe acid-base disturbances, particularly in a young adult, associated with prolonged seizures and cardiac arrhythmias may suggest the diagnosis. We report three cases of cocaine poisoning in which profound acid-base disturbances were present as well as acute neurological and cardiovascular compromise. Although changes in the acid-base status are well recognised in cocaine intoxication, such severe acidosis, with survival in two of the three patients, has not been well described. Possible causes for this acidosis are discussed.

\section{Case 1}

A 28 year old female was found unconscious at home. She was brought by ambulance to the $A \& E$ department. Two episodes of apnoea and a number of generalised seizures occurred during transfer. On arrival she was still convulsing and had an oropharyngeal airway in situ. Her Glasgow coma scale was 3, and both pupils were markedly dilated. She had a broad complex tachycardia of $140 / \mathrm{min}$ with an arterial blood pressure of $120 / 60 \mathrm{~mm} \mathrm{Hg}$.

Initial management consisted of controlling the seizures with a total of $20 \mathrm{mg}$ of diazepam. Her airway was secured by tracheal intubation and intermittent positive pressure ventilation begun. Subsequently her arterial systolic blood pressure decreased to $60 \mathrm{~mm} \mathrm{Hg}$ with the development of an idioventricular rhythm of $50 / \mathrm{min}$. Atropine $0.5 \mathrm{mg}$ intravenously restored her systolic arterial blood pressure to
$100 \mathrm{~mm} \mathrm{Hg}$ and her heart rate to $100 / \mathrm{min}$. Admission arterial blood gases (with supplementary oxygen) showed: $\mathrm{pH}$ 6.39, $\mathrm{PCO}_{2} 19.6 \mathrm{kPa}, \mathrm{Po}_{2} 35.3 \mathrm{kPa}$, base deficit -32 , and bicarbonate $9 \cdot 1 \mathrm{mmol} / \mathrm{litre} ; 50 \mathrm{mmol}$ of $8.4 \%$ sodium bicarbonate were infused and intermittent positive pressure ventilation continued. Arterial blood gases 20 minutes later showed: $\mathrm{pH} 6.6, \mathrm{PCO}_{2} 10.8 \mathrm{kPa}, \mathrm{Po}_{2}$ $29.5 \mathrm{kPa}$, base deficit -30 , and bicarbonate $8.0 \mathrm{mmol} /$ litre. A further $50 \mathrm{mmol}$ of $8.4 \%$ sodium bicarbonate were given intravenously. The patient's heart rhythm changed to a narrow complex tachycardia and her cardiovascular status stabilised.

Following gastric lavage and the administration of activated charcoal the patient was transferred to the intensive care unit. Further arterial blood gases showed: $\mathrm{pH} 7 \cdot 39$, $\mathrm{PCO}_{2} 3 \cdot 14 \mathrm{kPa}, \mathrm{Po}_{2} 39 \cdot 3 \mathrm{kPa}$, base deficit -11 , and bicarbonate $14.4 \mathrm{mmol} /$ litre. Electrolytes were as follows ( $\mathrm{mmol} / \mathrm{litre}$ ): sodium 143, potassium $5 \cdot 2$, chloride 105 , and urea $4 \cdot 7$. Creatinine was $105 \mu \mathrm{mol} /$ litre. An anion gap of $55 \mathrm{mmol} /$ litre was calculated. Chest and abdominal $x$ rays were normal. The patient was sedated and artificial ventilation continued overnight. She was extubated the next morning, 12 hours after admission, and subsequently made an uneventful recovery.

A toxicology screen was later shown to be positive for cocaine. The patient's boyfriend admitted that before her hospital admission she had been held in police custody for a short time under suspicion of possessing cocaine. It is thought that she swallowed cocaine in a "wrap".

\section{Case 2}

A 20 year old male was admitted to the A\&E department, having fallen through a first floor window onto the grass below. Initial examination showed him to be drowsy with a Glasgow coma scale of 13 . His arterial systolic blood pressure was recorded at $60 \mathrm{~mm} \mathrm{Hg}$ and his heart rate $140 / \mathrm{min}$. Deep lacerations were present on his scalp, arms, and right leg but there was no clinical evidence of any fractures.

Initial management consisted of supplementary oxygen and an intravenous infusion of $1000 \mathrm{ml}$ of colloid, followed by $1500 \mathrm{ml}$ of crystalloid. His arterial blood pressure improved to $100 / 60 \mathrm{~mm} \mathrm{Hg}$. Arterial blood gases obtained on admission (with supplementary oxygen) showed: $\mathrm{pH} 6 \cdot 7, \mathrm{PCO}_{2}$ $4.9 \mathrm{kPa}, \mathrm{PO}_{2} 20 \mathrm{kPa}$, base deficit -32 , and bicarbonate $4.0 \mathrm{mmol} /$ litre; $50 \mathrm{mmol}$ of $8.4 \%$ sodium bicarbonate were given intravenously and the patient's arterial systolic blood 
pressure stabilised at over $100 \mathrm{~mm} \mathrm{Hg.} X$ rays of his cervical spine, chest, pelvis, and skull were all normal. He continued to make an uneventful recovery. Subsequently, he admitted to having ingested cocaine in a "wrap", fearful of police custody.

\section{Case 3}

A 50 year old male was arrested at a drugs raid. $\mathrm{He}$ had been witnessed swallowing several plastic packets of a white substance. $\mathrm{He}$ subsequently complained of shortness of breath and was transferred to the $A \& E$ department.

In transit his level of consciousness deteriorated. On arrival he developed asystole and his left pupil dilated. Advanced cardiac life support procedures were begun. His trachea was intubated and his lungs ventilated. He subsequently reverted to a ventricular tachycardia and then into a sinus rhythm. Admission arterial blood gases showed: $\mathrm{pH}$ $6.56, \mathrm{PCO}_{2} 12.3 \mathrm{kPa}, \mathrm{Po}_{2} 33.2 \mathrm{kPa}$, base deficit -30 , and bicarbonate $8.5 \mathrm{mmol} /$ litre. He was given $50 \mathrm{mmol}$ of $8.4 \%$ sodium bicarbonate and transferred to the intensive care unit.

Continued ventilation of the patient's lungs and a further $100 \mathrm{mmol}$ of $8.4 \%$ sodium bicarbonate improved the acid-base status. Repeat arterial blood gases showed: $\mathrm{pH} 7 \cdot 3$, $\mathrm{PCO}_{2} 4.8 \mathrm{kPa}, \mathrm{PO}_{2} 25.5 \mathrm{kPa}$, base deficit -13 , and bicarbonate $13.5 \mathrm{mmol} /$ litre. A computerised tomography scan of the head revealed cerebral oedema and a small amount of subarachnoid blood. A toxicology screen was positive for cocaine and diazepam. The patient subsequently developed acute renal failure and had a further asystolic arrest on day 4 with unsuccessful resuscitation.

\section{Discussion}

Cocaine abuse in Britain is increasing. Home Office statistics for the period 1987 to 1991 show a rise in the number of reported cocaine addicts from 800 to $1525 .^{1}$ This is almost certainly a gross underestimate of the true figure. In the United States the problem is substantially greater, with as many as five million people using it regularly. ${ }^{2}$ From these statistics it is likely that the number of patients presenting to British A\&E departments with cocaine intoxication will continue to increase.

Many features of cocaine poisoning have been well described. These include agitation, hallucinations, paranoid psychoses, mydriasis, hypertension, cardiac dysrhythmias, hyperthermia, seizures, and respiratory arrest. ${ }^{34}$ Other less commonly described complications include acute myocardial infarction, ${ }^{5}$ cerebrovascular accidents, ${ }^{6}$ gangrenous bowel, ${ }^{7}$ and pneumopericardium.

Cocaine prevents the presynaptic reuptake of noradrenaline and dopamine, leading to a surplus of these neurotransmitters at the postsynaptic receptor sites. This in turn leads to increased sympathetic nervous system activity, resulting in many of the effects described above, including arrhythmias, generalised seizures, and agitation. Previously, the acidaemia associated with cocaine poisoning has been attributed to the occurrence of these generalised seizures. ${ }^{9}$ Experiments in dogs showed that when these animals were infused with cocaine they all convulsed, and were all severely acidaemic just before death, ${ }^{10}$ with blood lactate levels reaching $6.1 \mathrm{mg} / \mathrm{dl}$. In our paper, case 1 presented with status epilepticus and an initial blood $\mathrm{pH}$ of 6.39 . The high anion gap was consistent with a severe lactic acidosis and would be expected following convulsant activity. However, such severe changes in the blood $\mathrm{pH}$ are not typical in generalised seizures on their own, Orringer et al ${ }^{11}$ noting a $\mathrm{pH}$ as low as $6 \cdot 86$. This suggests that other mechanisms also contributed to such a severe acidosis as occurred in our patients. The prehospital respiratory compromise explains a respiratory component to the acidosis in cases 1 and 3. In case 2 there was no history of seizures or signs of hypovolaemic shock but he did have a profound metabolic acidosis. A similar case has been reported once previously. Drake et $a l^{12}$ reported that exhaustive exercise in an agitated patient with cocaine poisoning may have contributed significantly to the acidaemia. It is unclear whether this was a factor in our second case. They also suggested that the acidosis might be related to the action of cocaine in inhibiting reuptake of noradrenaline at the nerve terminal, which can result in a lactic acidosis as occurs in phaeochromocytoma. In a dog model, ${ }^{13}$ a dose related pure metabolic acidosis was induced at $5 \mathrm{mg} / \mathrm{kg}$ of cocaine but not by $3 \mathrm{mg} / \mathrm{kg}$.

The acidosis in severe cocaine intoxication therefore arises from a number of mechanisms. Once the respiratory component has been eliminated and seizure activity aborted with therapeutic manoeuvres, evidence suggests that cocaine itself produces a lactic acidosis. The likely mechanism for this would seem to be related to its primary action which produces a surplus of neurotransmitters at postsynaptic receptor sites. This can lead to increased cellular metabolism, peripheral vasoconstriction causing hypoperfusion, and increased glycolysis. ${ }^{14}$ However, further work is required to elucidate the exact steps involved in relation to the severity of the intoxication.

In our third case, the patient did not convulse but did have a profound respiratory and metabolic acidosis. In addition, his rapid deterioration and cardiorespiratory arrest just before arrival in the $A \& E$ department would suggest a possible direct cardiac effect. This is well recognised, ${ }^{5}$ with increases in heart rate, systolic blood pressure, and myocardial oxygen demand being particularly hazardous to those with underlying fixed coronary artery disease. Our patient was 50 years old. In younger patients the cause may be a transient focal event of coronary thrombosis or spasm. ${ }^{16}$ Cardiovascular instability occurred in the first and second cases as well. However, the mechanism here is likely to have been related to the severe acidaemia. This is supported by the fact that our patients' cardiovascular indices improved following the administration of $8.4 \%$ sodium bicarbonate. Ventilatory 
support, judicious correction using $50 \mathrm{ml}$ boluses of bicarbonate, assessment of the response by repeated arterial blood gases, and treatment of the underlying cause is essential. The depressant effect on ventricular function has been documented as being directly related to cocaine ${ }^{17}$ and is associated with a decrease in coronary blood flow.

The arrhythmogenicity of cocaine, which may be due to the direct effect of the drug or to its effects on catecholamines, can result in a variety of ventricular arrhythmias as well as asystole. ${ }^{1819}$ This was confirmed in case 1 , where an initial broad complex tachycardia deteriorated to an idioventricular bradycardia before responding to a combination of atropine, intravenous bicarbonate, and hyperventilation to correct hypercarbia. In case 3 the rhythm presentation was one of asystole with a severe combined metabolic and respiratory acidosis.

The history of events leading up to the collapse would normally yield the likely diagnosis, but such patients or their friends and relatives are often reluctant to help initially in this regard. The "body packer" syndrome is well known ${ }^{20}$ and describes individuals who carefully package their illicit contraband before ingesting the drugs for the purpose of smuggling. "Body stuffers", on the other hand, perform a much riskier form of ingestion as they hurriedly attempt to conceal an illegal drug to avoid arrest. Thus in this latter group the loose packaging which has been prepared for street sale is much more likely to rupture, with resultant toxicity. ${ }^{21}$ Our three cases were all examples of this practice. The type of material and method of wrapping the cocaine are also important factors in the onset and likelihood of toxicity developing. ${ }^{22}$ Cellophane bags are much more likely to rupture than substances packaged in condoms.

This has important implications on decision making as to whether surgical intervention is required to remove retained packets from the patient's gastrointestinal tract. Conservative treatment allowing the packets to pass naturally has been advocated. ${ }^{23}$ This will depend upon the clinical state and whether the packets have passed the pylorus of the stomach, failure to do so being an indication for surgical intervention. ${ }^{24}$ Activated charcoal, which actively adsorbs cocaine, is an important early adjunct to treatment. ${ }^{25}$

In summary, management of severe cocaine poisoning is essentially supportive but early diagnosis will allow the clinician to anticipate complications and possibly prevent further release from poorly wrapped packets. A high index of suspicion for cocaine intoxication must be maintained in a comatose adult presenting with an inconsistent history, severe acidosis, seizures, or arrhythmias, especially when other common causes have been excluded. Correction of such an acidosis by ventilatory support and judicious therapeutic manoeuvres is important and may contribute significantly to stabilising the cardiovascular dysfunction.

1 Home Office, United Kingdom. Statistics of drug addicts notified to the Home Office, United Kingdom 1992. Home Office Statistical Bulletin 1993;9:19.

2 Abelson HI, Miller JD. A decade of trends in cocaine use in the household population. Natl Inst Drug Abuse Res Monogr Ser 1985;61:35-49.

3 Cregler LL, Mark H. Medical complications of cocaine abuse. $N$ Engl f Med 1987;315:1495-500.

4 Panacek EA. Cocaine: medical toxicity. In Vincent JL, ed. Yearbook of intensive care and emergency medicine. New Yearbook of intensive care and emergenc.

5 Cregler LL, Mark H. Relation of acute myocardial infarction to cocaine abuse. Am $\mathcal{F}$ Cardiol 1985;56:794

6 Lichtenfeld PJ, Rubin DB, Feldman RS. Subarachnoid haemorrhage precipitated by cocaine snorting. Arch Neurol 1984;41:223-4.

7 Nalbandian H, Sheth N, Dietrich R, Georgiou J. Intestinal ischaemia caused by cocaine ingestion: a report of two cases. Surgery 1985;97:374-5.

8 Adrouny A, Magnusson P. Pneumo-pericardium from cocaine inhalation. N Engl f Med 1985;313:48-9.

9 Jonsson S, O'Meara M, Yound JB. Acute cocaine poisoning: importance of treating seizures and acidosis. Am $\mathcal{F}$ Med 1983;75:1061-4.

10 Catravas JD, Waters IW, Walz MA, Davis WM. Acute cocaine intoxication in the conscious dog: pathophysiologic profile of acute lethality. Arch Int Pharmacodyn 1978;235:328-40.

11 Orringer CE, Eustace JC, Wunsch CD, Gardner L. Natural history of lactic acidosis after grand mal seizures. $N$ Engl
hinger CE, Eustace JC, Wunsch CD, Gardner L. Natural f Med 1977;297:796-9.

12 Drake TR, Henry T, Marx J, Gabow PA. Severe acid base abnormalities associated with cocaine abuse. $\mathcal{F}$ Emerg Med 1990;8:331-4

13 Kabas JS, Blanchard SM, Matsuyama Y, Long JD, Hoffman GW, Ellinwood EH, et al. Cocaine mediated impairment of cardiac conduction in the dog. A potential mechanism for sudden death after cocaine. F Pharmacol Exp Ther 1990;252:185-91.

14 Stevens DC, Campbell JP, Carter JE, Watson WA. Acid base abnormalities associated with cocaine toxicity in emergency department patients. Clin Toxicol 1994;32: 31-9.

15 Mueller PD, Benowitz NL, Olson KR. Cocaine. Emerg Med Clin North Am 1990;8:481-93.

16 Howard RE, Hueter DC, Davis GJ. Acute myocardial infarction following cocaine abuse in a young woman with infarction following cocaine abuse in a young wom

17 Fraker TD, Temesy-Armos PN, Brewster PS, Wilkerson RD. Mechanism of cocaine induced myocardial depression in dogs. Circulation 1990;81:1012-6.

18 Nanji AA, Filipenko JD. Asystole and ventricular fibrillation associated with cocaine intoxication. Chest 1984;85: 132-3.

19 Benchimol A, Bartall H, Desser KB. Accelerated ventricular rhythm and cocaine abuse. Ann Intern Med 1978;88: 519-20.

20 McCarron MM, Wood JD. The cocaine 'body packer' syndrome. $¥ A M A$ 1983;250:1417-20.

21 Roberts JR, Price D, Goldfrank LG, Hartnett L. The bodystuffer syndrome: a clandestine form of drug overdosage. Am f Emerg Med 1986;4:24-7.

22 Aks SE, Vander Hoek TL, Hryhorczuk DO, Negrusz A, Tebbutt I. Cocaine liberation from body packets in an in vitro model. Ann Emerg Med 1992;21:1322-5.

23 Caruna DS, Weinbach B, Georg DL, Gardner LB. Cocaine packet ingestion. Ann Intern Med 1984;100:73-4.

24 Ramrakha P, Barton I. Drug smuggler's delirium. BMF 1993;306:470-1.

25 Tomaszewski CA, Brent J, Wathan J, Wathan J. Cocaine adsorption by activated charcoal in vitro. Vet Hum Toxicol 1990;32:350. 